\title{
ERRATUM
}

\section{Stroke prevention by direct revascularization for patients with adult- onset moyamoya disease presenting with ischemia}

TO THE EDITOR: We appreciate the publication of our paper, "Stroke prevention by direct revascularization for patients with adult-onset moyamoya disease presenting with ischemia" (J Neurosurg [epub ahead of print December 4, 2015; DOI: 10.3171/2015.6.JNS151105]). Unfortunately, an error occurred during production of our paper, and we didn't catch it while reviewing the page proofs.

The footnotes in Table 3 were misplaced and may have rendered the data confusing to the readers.

We are pleased to have the opportunity to rectify this error. The corrected Table 3 is shown on this page. It was posted online as of January 8, 2016, and also appears in the printed version of the paper in this issue.

Jae Seung Bang, MD

Seoul National University Hospital, Seoul, Repubic of Korea
TABLE 3. Risk factor analysis for 201 patients who had been followed up for more than 5 years*

\begin{tabular}{lcclcccc}
\hline & \multicolumn{2}{c}{ Univariate } & & \multicolumn{3}{c}{ Multivariate } \\
\cline { 2 - 3 } \cline { 6 - 7 } \multicolumn{1}{c}{ Variable } & OR & $p$ Value & & OR & $p$ Value & $95 \% \mathrm{Cl}$ \\
\hline Revascularization & 0.277 & 0.069 & & 0.160 & $0.031 \dagger$ & $0.030-0.845$ \\
\hline Age & 1.009 & 0.762 & & 0.996 & 0.894 & $0.937-1.059$ \\
\hline Male sex & 0.721 & 0.622 & & 0.634 & 0.502 & $0.168-2.394$ \\
\hline Suzuki stage & 0.961 & 0.924 & & 0.549 & 0.268 & $0.190-1.586$ \\
\hline
\end{tabular}

* Statistical analysis was conducted with binominal logistic regression.

† Statistically significant.

CORRESPONDING ARTICLE See pp 1788-1793.

INCLUDE WHEN CITING

Published online January 8, 2016; DOI: 10.3171/2015.12.JNS151105a.

CAANS, 2016 